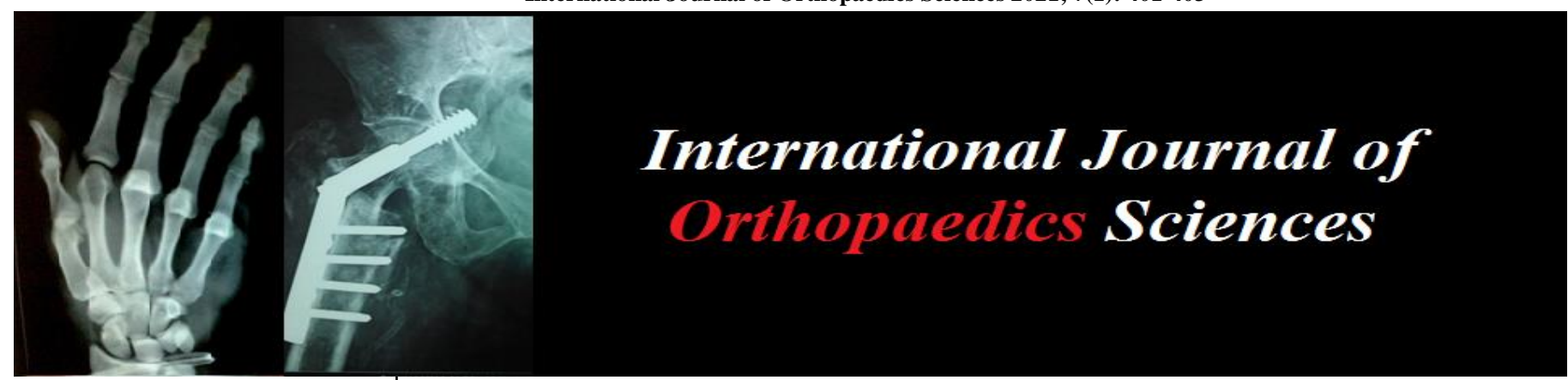

E-ISSN: 2395-1958

P-ISSN: 2706-6630

IJOS 2021; 7(1): 401-403

(C) 2021 IJOS

www.orthopaper.com

Received: 05-11-2020

Accepted: 13-12-2020

Wajahat Ahmad Mir Resident in Department of Orthopaedics, Government Medical College, Anantnag, Jammu and Kashmir, India

Rasiq Rashid

Resident in Department of Orthopaedics, Government Medical College, Anantnag, Jammu and Kashmir, India

Javaid Ahmad Ganaie Resident in Department of Orthopaedics, Government Medical College, Anantnag, Jammu and Kashmir, India
Corresponding Author: Javaid Ahmad Ganaie Resident in Department of Orthopaedics, Government Medical College, Anantnag, Jammu and Kashmir, India

\section{Outcome of percutaneous kirschner wire fixation for supracondylar fractures of humerus in elderly comorbid patients}

\author{
Wajahat Ahmad Mir, Rasiq Rashid and Javaid Ahmad Ganaie
}

DOI: https://doi.org/10.22271/ortho.2021.v7.i1g.2517

Abstract

Background: Management of supracondylar fractures in young adults has evolved over the last two decades but management of these fractures in elderly comorbid patients is still matter of debate. In this study we present the outcome of supracondylar fractures of humerus in elderly comorbid patients treated by closed reduction and percutaneous kirschner wires crisscross fashion.

Results: Mean age in our study was 64.5 years, with F:M ratio of 10:6. Left sided involvement was seen in 9 patients while right side was involved in 7 patients. The mean Mayo Elbow Performance Score at final follow up was 91.56 and was excellent in 11(68.75\%) patients, good in 4(25\%) patients, fair in $1(6.25 \%)$ patient. Mean time to union was 6.4 weeks.

Conclusion: When aided with appropriate immobilization and timely rehabilitation, closed reduction \& percutaneous kirschner wire fixation is a viable option for management of supracondylar fractures in elderly comorbid patients.

Keywords: Supracondylar fracture, kirschner wire, mayo elbow performance score

\section{Introduction}

Supracondylar fractures of humerus in adults are relatively uncommon and constitute about 2 to $6 \%$ of all the fractures in adults ${ }^{[1]}$. Literature related to the management of supracondylar fractures is sparse and the treatment of supracondylar humerus fractures in adults is thus not well established in that sparse literature ${ }^{[2]}$. Majority of these fractures occur in elderly patients with lesser bone stock due to low energy trauma ${ }^{[3]}$. Rigid internal fixation of such osteopenia fractures poses a challenge to the treating surgeon and is prone to failure as the distal fragment is too small and is covered with articular cartilage ${ }^{[4]}$. Moreover the extensive exposure needed for open reduction and internal fixations adds to the morbidity of already morbid patients hence making the rehabilitation process more difficult ${ }^{[5,6]}$.

The aim of this study was to evaluate a minimally invasive method to fix these fractures with the help of kirschner wires in elderly morbid patients.

\section{Material and methods}

This prospective interventional study was carried out in Govt. Medical College Anantnag J\&K India from Jan. 2019 to Dec. 2020 after obtaining clearance from institutional ethical committee. A total of 16 elderly comorbid patients with supracondylar were included in this study.

\section{Inclusion criteria}

- All sexes.

- Age group-55 to 75 years.

- Non comminuted supracondylar fractures.

- Patients unfit for general anesthesia.

\section{Exclusion criteria}

- Associated neurovascular injury. 
- Supracondylar fractures with intercondylar extension.

- Injury more than 3 weeks old.

\section{Operative procedure}

The surgery was done in supine position under local anesthesia (periosteal infiltration). Closed reduction was done under $\mathrm{C}$ arm guidance and fracture was fixed percutaneously with two kirschner wires in crisscross fashion. After fixing the fracture the arm was put in a long arm splint with the elbow in $90^{\circ}$ of flexion and the wrist in neutral rotation.

\section{Follow up}

After discharging the patients, they were called for regular follow ups at 2 weekly intervals. The splint was replaced with the hinged elbow brace at 2 weeks follow up, and gentle assisted range of motion exercise was started

The range of motion was progressively increased as tolerated. Hinged elbow brace was removed at 4 weeks and active range of movements was started. Kirschner wires were removed at 6 weeks. Final assessment was done at 6 months follow up using Mayo Elbow Performance Score ${ }^{[7]}$ (MEPS) which takes into consideration the pain score, Range of motion, stability and function. MEPS of 90 or more is considered as excellent, score of 75-89 is considered good, 60-74 is considered as fair while a score of less than 60 is considered as poor.

\section{Results}

In our study the mean age was 64.5 years (range 55 to 75 years). Females outnumbered males in our study with the female: male ratio of 10:6. Left side was involved in $9(56.25 \%)$ patients while $7(43.75 \%)$ patients right sided fracture. In 14(87.5\%) patient's simple fall was responsible for the fracture while in only $2(12.5 \%)$ patients road traffic accident was responsible for the fracture.
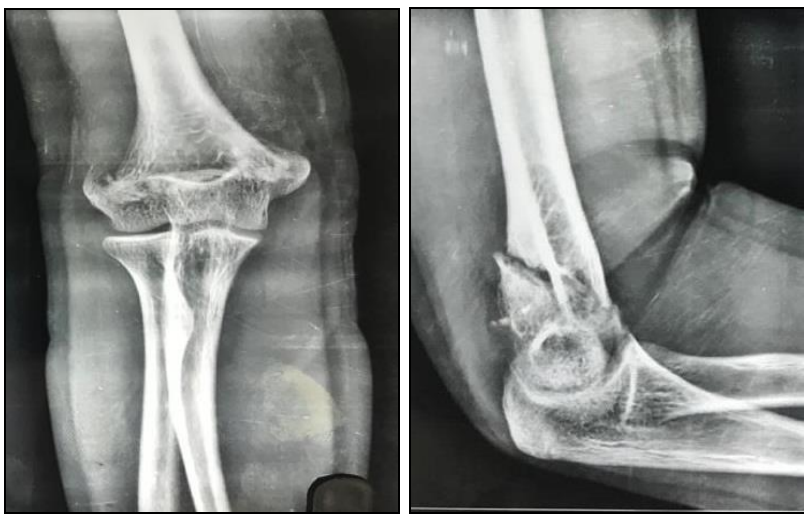

Fig 1: Preoperative AP \& lateral view of the fracture
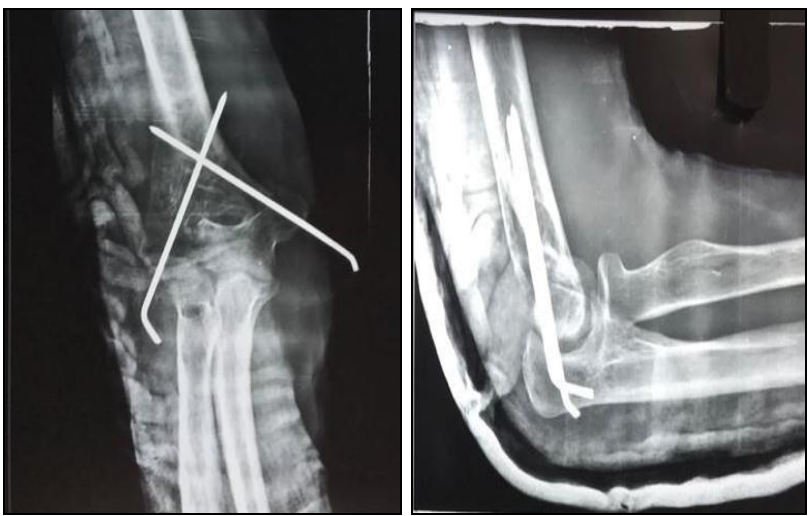

Fig 2: Postoperative AP \& lateral view of the fracture
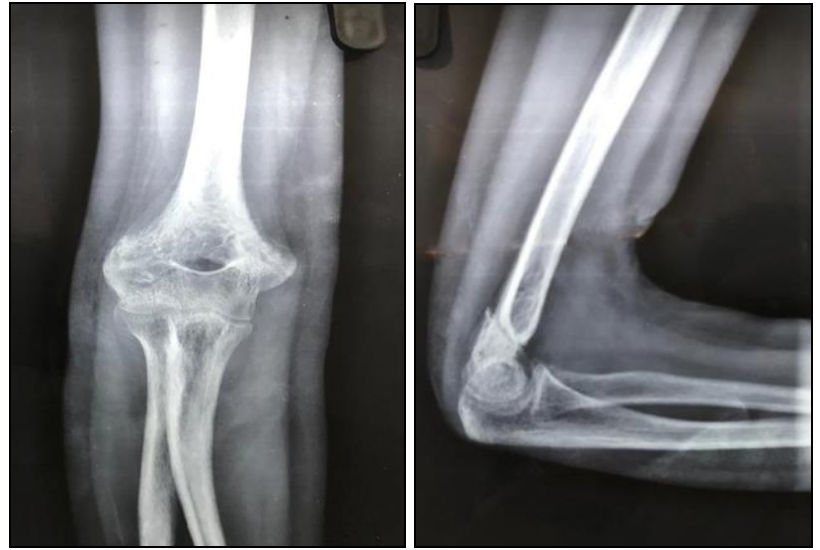

Fig 3: Final follow up AP \& lateral view of the fracture

The mean Mayo Elbow Performance Score at final follow up was 91.56 and was excellent in 11(68.75\%) patients, good in $4(25 \%)$ patients, fair in $1(6.25 \%)$ patient. Mean time to union was 6.4 weeks. In our study $2(12.5 \%)$ patients had pin site discharge at 2 weeks follow up which subsided with oral antibiotics, 3(18.75\%) patients experienced stiffness. We encountered no cases of nonunion or iatrogenic nerve injury.

\section{Discussion}

Management of supracondylar humerus fractures with long arm cast is not advocated as prolonged immobilization required is associated with stiffness of elbow joint that leads to functional limitation especially in elderly debilitated patients ${ }^{[8,9]}$. Open reduction \& internal fixation with plating of supracondylar fractures has a high complication rates in such cases ${ }^{[10,11]}$. Simone et al. ${ }^{[10]}$ experienced complications with dual plating in $40 \%$ of their cases. Closed reduction and percutaneous Kirschner wire fixation for supracondylar fractures not only reduces post-operative morbidity but also has biological advantage in the form of preservation of fracture hematoma ${ }^{[10]}$. We observed a mean MEPS of 91.56 in our study which is comparable with the study done by Park JS et al. ${ }^{[12]}$ using crisscross-type screw fixation for transcondylar fractures of distal humerus in elderly patients. Excellent to good results based on MEPS were seen 94\% patients in our study. Similar results were obtained by Vala $\mathrm{P}$ et al. ${ }^{[13]}$ in their study. Our complication rates were also comparable with other studies in literature ${ }^{[12,14]}$.

\section{Conclusion}

Based on our results we can conclude that closed reduction \& percutaneous kirschner wire fixation is a minimally invasive $\&$ a viable option for management of supracondylar fractures in elderly patients with significant medical or surgical comorbidities. However appropriate immobilization and timely rehabilitation is necessary to produce an irreproachable outcome.

\section{References}

1. Korner J, Lill H, Müller LP et al. The LCP-concept in the operative treatment of distal humerus fractures-biological, biomechanical and surgical aspects. Injury 2003;34(2):B20-30.

2. Ray PS, Kakarlapudi K, Rajsekhar C et al. Total elbow arthroplasty as primary treatment for distal humeral fractures in elderly patients. Injury 2000;31(9):687-92.

3. Paryavi E, O'Toole RV, Frisch HM et al. Use of 2 column screws to treat transcondylar distal humeral fractures in geriatric patients. Tech Hand up Extrem. Surg 
2010;14(4):209-213.

4. Hausman M, Panozzo A. Treatment of distal humerus fractures in the elderly. Clin Orthop Relat Res. 2004; 425:55-63.

5. Armstrong AD, Yamaguchi K. Total elbow arthroplasty and distal humerus elbow fractures. Hand Clin. 2004; 20(4):475-483.

6. Popovic D, King GJ. Fragility fractures of the distal humerus: what is the optimal treatment? J Bone Joint Surg. Br 2004;94(1):16-22.

7. Morrey BF, An KN. Functional evaluation of the elbow. In: Morrey BF, editor. The elbow and its disorders. 3rd ed. Philadelphia: WB Saunders, 2000, 82.

8. Aitken GK, Rorabeck CH. Distal humeral fractures in the adult. Clin Orthop Relat Res 1986;207:191-197.

9. Gupta R. Intercondylar fractures of the distal humerus in adults. Injury. 1996; 27(8):569-572.

10. Simone JP, Streubel PN, Sanchez-Sotelo J et al. Low transcondylar fractures of the distal humerus: results of open reduction and internal fixation. J Shoulder Elbow Surg. 2014; 23(4):573-578.

11. Robinson CM, Hill RM, Jacobs N, Dall G, Court-Brown CM. Adult distal humeral metaphyseal fractures: epidemiology and results of treatment. J Orthop Trauma 2003;17(1):38-47.

12. Park JS, Kim YT, Choi SJ. Crisscross-type screw fixation for transcondylar fractures of distal humerus in elderly patients. Arch Orthop Trauma Surg 2015;135:1-7.

13. Vala P, Devda A, Parikh D et al. Evaluation of results of surgical management of closed intra-articular fractures of distal end Humerus. National Journal of Clinical Orthopaedics 2017;1(2):43-49.

14. Paryavi E, O'Toole RV, Frisch HM et al. Use of 2 column screws to treat transcondylar distal humeral fractures in geriatric patients. Tech Hand Surg 2010;14:209-213. 